This is a Accepted Manuscript of the following published document:

Olmos, D., González-Gaitano, G. \& González-Benito, J. (2015). Effect of a silica nanofiller on the structure, dynamics and thermostability of LDPE in LDPE/silica nanocomposites. RSC Advances, 5(44), pp. 34979-34984.

DOI: $10.1039 / \mathrm{c} 5 \mathrm{ra} 00738 \mathrm{k}$

(C) The Royal Society of Chemistry 2015 


\title{
Effect of a silica nanofiller on the structure, dynamics and thermostability of LDPE in LDPE/silica nanocomposites
}

\author{
Dania Olmos $^{a}$, Gustavo González-Gaitano ${ }^{b}$ and Javier González Benito ${ }^{a^{*}}$
}

\begin{abstract}
The effect of the presence of silica nanoparticles on the structure, thermal stability and dynamics of low density polyethylene, LDPE, has been studied. Different loads of nanoparticles were dispersed within a LDPE matrix using high energy ball milling (HEBM) as a preliminary processing step to ensure a 10 uniform dispersion of nanofiller to obtain nanocomposites in the form of films by hot pressing. The monitoring of the FTIR-ATR spectra of the samples as a function of the temperature has proven as a convenient method to study the interactions at a molecular scale between polyethylene chains and the nanofiller. Band splitting observed in the bending and rocking modes of the ethylene groups indicated formation of crystalline phases whereas the analysis of absorbance band ratios from the stretching 15 vibrations of PE accounted for the behavior of the polymer bulk. No evidence of strong polymer-filler interactions were found with the exception of a thermal relaxation process observed at $55{ }^{\circ} \mathrm{C}$. Structural, morphological and thermal characterization of the nanocomposites did not reveal remarkable changes at low loads of filler, indicating that in the case of LDPE-silica nanocomposites, where relatively weak interactions between the polymer and filler occur, the volume fraction of nanoparticles must be relatively 20 high in order to produce changes in the bulk properties.
\end{abstract}

\section{Introduction}

During the past twenty years many efforts have been done in understanding the real effect of the incorporation of nanoparticles into polymers to form a a nanocomposite material [1]. Changes in 25 the bulk properties of polymers under the influence of nanofillers may have the origin either in the intrinsic features of the nanoparticles (electrical, optical, mechanical, properties) or be ascribed to structural and morphological changes induced in the polymer by the presence of the nanoparticles. In the first case, 30 usually a simple model based on the rule of mixtures can be applied to predict the behaviour. The second one, however, is more difficult to ascertain, as it mainly depends on the specific interactions taking place between the particles and the polymer chains, which in turn are connected to the size and aspect ratio of 35 the particles. Due to the increased surface to volume ratio of nanoparticles there is a large fraction of interphase in a nanocomposite, in which a gradient of physico-chemical properties exists from one phase, the particle, to the other, the polymer, which is going to be decisive in the final properties of 40 the material. Quite often, even small amounts of the nanofiller may produce important consequences on the final properties of
${ }_{50}$ composites by analysing the bands of different absorbing groups as a function of the curing time with the temperature $[16,17]$. The use of FTIR spectroscopy with the aid of fluorescence has also allowed the study of processes such as chemical reactions [18], phase separation [19] or water absorption [20]. More 55 recently, the analysis of FTIR-ATR absorption bands has been used to study of the changes accompanying interfacial conformations and molecular structure in PMMA-silica nanocomposites [8, 21, 22].

A factor of paramount importance in the characterization of 60 this type of materials is the uniform dispersion of the nanoparticles within the polymer to avoid effects derived from the potential aggregation of the particles. Thus, different approaches have been described in the literature to achieve a good dispersion of nanoparticles into polymer matrices, as 65 chemical modification of the surface of the nanoparticles/polymeric matrices to generate specific functional groups, in situ polymerization, or sol-gel methods to create nanoparticles within the polymer [23], among other methods. However, when filler loadings are usually higher than $5 \%$ by 70 weight and for particles with diameters under $50 \mathrm{~nm} \mathrm{[24]} \mathrm{to} \mathrm{get} \mathrm{a}$ uniform dispersion of the nanofiller proves to be a challenge. A 
influence of the presence of the nanofiller in the structure, morphology, thermodegradation and dynamics of the polymeric matrix. A procedure based on monitoring the evolution of selected ATR bands of the LDPE as a function of temperature 5 that can be applied to other matrices has been proposed that permits to obtain information at a molecular scale about the structure, specific interactions, and melting process of the semicrystalline polymer under the influence of the silica nanofiller,

\section{${ }_{10}$ Experimental}

\section{Materials}

Commercial low density polyethylene, LDPE (melt index $25.00 \mathrm{~g} / 10 \mathrm{~min}, 190{ }^{\circ} \mathrm{C} / 2.16 \mathrm{~kg}$, ASTM D 1238 and $0.93 \mathrm{~g} \mathrm{~cm}^{-1}$ density) was supplied by Aldrich. Fumed silica nanoparticles $15\left(200 \mathrm{~m}^{2} \mathrm{~g}^{-1}\right.$ surface area, $2.2 \mathrm{~g} / \mathrm{cm}^{3}$ density, $14 \mathrm{~nm}$ of diameter) were supplied by Sigma-Aldrich.

\section{Sample preparation}

LDPE and its mixtures with $\mathrm{SiO}_{2}$ nanoparticles were ground under cryogenic conditions in a mill RESCHT MM 400. $16 \mathrm{~mL}$

20 of the raw materials were introduced into vials with one stainless steel ball $(2.5 \mathrm{~cm} \varnothing)$. The vials were hermetically closed with Teflon spacers and immersed in liquid nitrogen for $15 \mathrm{~min}$ prior milling at $28 \mathrm{~Hz}$ for 5 minutes. This cycle was repeated until reaching one hour of active milling.

25 Nanocomposites were prepared in the form of films from the milled mixtures by hot pressing using a Microtest S.A. pressing machine. The milled powders were placed inside an aluminium mould sandwiched by two Teflon sheets as anti-adherent. Powders were subjected to a constant load of $20 \mathrm{kN}$ at $150{ }^{\circ} \mathrm{C}$ for 308 minutes. Then, the samples were left to cool down at room temperature up to $50^{\circ} \mathrm{C}$ under the same constant pressure.

\section{Experimental techniques and methods}

Thermogravimetric analysis, TGA, was carried out using a thermal analyzer Mettler TGA/SDTA851 with multisampler 35 device. All the samples were measured in $50 \mu \mathrm{L}$ Pt crucibles under nitrogen atmosphere. To study the kinetics of the thermodegradation process of the nanocomposites different heating rates $\left(10,15,20\right.$ and $\left.25^{\circ} \mathrm{C} / \mathrm{min}\right)$ were used.

Melting and crystallization processes were monitored using a 40 Mettler Toledo 822e differential scanning calorimeter under nitrogen atmosphere using the following thermal cycle: i) a dynamic heating step from $35^{\circ} \mathrm{C}$ to $150^{\circ} \mathrm{C}$ at $10^{\circ} \mathrm{C} / \mathrm{min}$; ii) an isothermal step at $150^{\circ} \mathrm{C}$ for 1 hour; iii) a dynamic cooling step from $150^{\circ} \mathrm{C}$ to $35^{\circ} \mathrm{C}$ at $10^{\circ} \mathrm{C} / \mathrm{min}$; iv) an isothermal step at $35^{\circ} \mathrm{C}$

45 for $3 \mathrm{~min}$; and v) a dynamic heating step from $35^{\circ} \mathrm{C}$ to $150^{\circ} \mathrm{C}$ at $10{ }^{\circ} \mathrm{C} / \mathrm{min}$. The experiments were carried out in $40 \mu \mathrm{L}$ aluminium crucibles.

Morphological characterization of the films was carried out using a scanning probe microscope MultiMode Nanoscope IVA

50 (Veeco), AFM, at ambient conditions in tapping mode with etched silicon probes $(40 \mathrm{~N} / \mathrm{m})$. To ensure the same thermal history of all samples, the films underwent exactly the same thermal cycle used for calorimetric studies using the same calorimeter. The DSC crucibles with the samples were then glued 55 on AFM metal discs with epoxy resin. Then the cover of the DSC capsule was carefully removed with a razor blade and subsequently blown with nitrogen to clean the surfaces, prior to AFM visualization.

A Nicolet Avatar 360-Golden Gate diamond FTIR-ATR with 60 temperature controller was used to study the LDPE and the nanocomposites as a function of temperature. Samples were kept at $140^{\circ} \mathrm{C}$ on the diamond of the ATR accessory for one hour to erase the thermal history before recording the IR spectra as a function of temperature. The dynamic experiment was carried out ${ }_{65}$ cooling down from $140^{\circ} \mathrm{C}$ to $40^{\circ} \mathrm{C}$ at a cooling rate of $50^{\circ} \mathrm{C} / \mathrm{h}$.

\section{Results and discussion}

\section{Thermal stability and DSC studies}

The mass losses as a function of temperature of the nanocomposites with different $\mathrm{SiO}_{2}$ contents are shown in Figure 701 for a heating rate of $10^{\circ} \mathrm{C} / \mathrm{min}$.

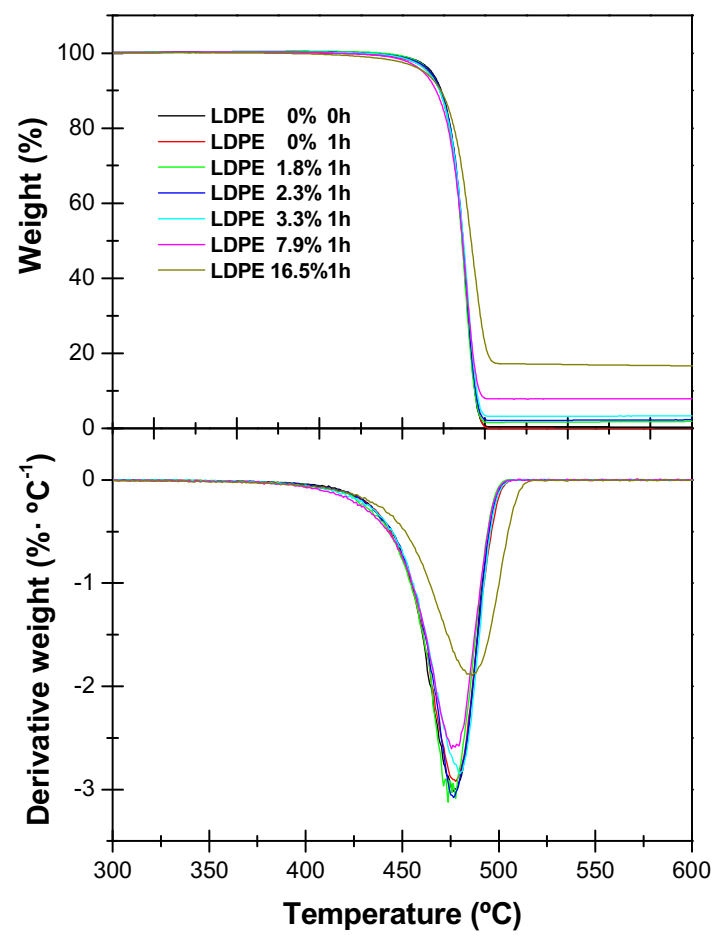

Fig. 1 TGA curves (top) and their derivatives DTGA (bottom) for 75 the neat LDPE and its nanocomposites: LDPE 1.8\%; LDPE $2.3 \%$; LDPE $3.3 \%$; LDPE $7.9 \%$; LDPE $16.5 \%$ of $\mathrm{SiO}_{2}$ nanoparticles.

For the rest of temperature ramps studied similar profiles 80 were obtained, the only difference being the temperature at which the decomposition rate is maximum, $\mathrm{T}_{\max }$, as expected taking into account the kinetic character of the thermal decomposition process. For low loads of nanofiller, the temperature of thermal decomposition, does not change significantly with the content of 85 nanoparticles $\left(\mathrm{T}_{\max }=477{ }^{\circ} \mathrm{C}\right.$, Figure 1 , top). This is better perceived in the first derivative, DTGA plot (Figure 1, bottom), which shows how the degradation temperature increases significantly only when the amount of silica nanoparticles is considerable, reaching a value of $\mathrm{T}_{\max }=486{ }^{\circ} \mathrm{C}$ for LDPE filled 90 with $16.5 \mathrm{wt} \%$ of $\mathrm{SiO}_{2}$.

A kinetic study of the process of thermal decomposition has been performed according to the Kissinger's method via the analysis of the TGA curves of the samples at different heating rates $[29,30]$. Activation energies, $E_{a}$, of $270 \pm 20 \mathrm{~kJ} / \mathrm{mol}$ were 95 obtained regardless the composition. Similar values have been reported for this polymer in the literature [31], which indicates that the presence of nanoparticles has not a noticeable catalytic or inhibiting effect on the decomposition of LDPE. This result 
evidences no specific interactions between the polar surface of the silica nanoparticles and the non-polar LDPE chains, in accordance to the different chemical nature of both.

Regarding the calorimetry studies, different parameters 5 obtained from the DSC scans have been considered: the temperature of crystallization obtained at the exothermic peak, $T_{c p}$, the average temperature of crystallization, $\left\langle T_{c}>\right.$, by considering the DSC exothermic peak as a distribution of temperatures, and the degree of crystallization, $\chi_{c}$. These 10 parameters have been plotted in Fig. 2. Upon cooling, the temperature of crystallization and the degree of crystallization remain constant with the content of $\mathrm{SiO}_{2}$ within the experimental uncertainty, although the difference between $T_{c p}$ and $\left\langle T_{c}>\right.$ seems to increase with the content of silica. This may indicate that the 15 contribution of a particular crystalline domain increases with the content of particles but without modifying the overall crystallinity of the polymeric matrix, which remains practically constant at a value around 0.45 .

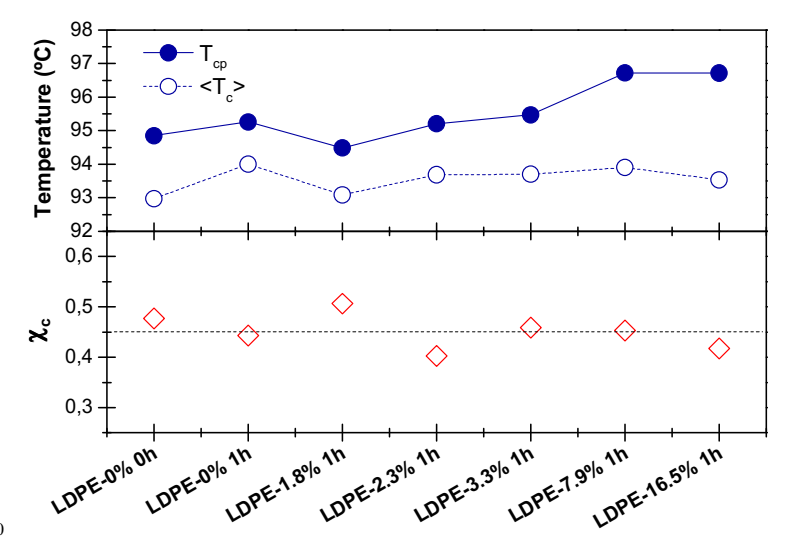

Fig. 2 Crystallization temperatures, $T_{c p}$ and $\left\langle T_{c}\right\rangle$, and degree of crystallinity, $\chi_{c}$, taken from the exothermic peaks in the cooling scans as a function of the content of $\mathrm{SiO}_{2}$ (the dotted line 25 corresponds to the average value of the degree of crystallinity calculated from all the samples).

\section{Morphological analysis by AFM}

Figure 3 shows the AFM height images obtained for the 30 nanocomposites with different amounts of nanosilica. The nonmilled LDPE (LDPE 0h) shows a surface with randomly distributed needle-like structures or lamellae that may correspond to relatively large crystalline domains (spherullites). After milling for $1 \mathrm{~h}$ (LDPE $1 \mathrm{~h}$ ) an important contribution of crystalline 35 domains with longer and thinner lamellar structures can be observed. The introduction of silica nanoparticles (LDPE-1.8\% $\mathrm{SiO}_{2}$ 1h) induces another change in morphology, more clearly seen in samples LDPE-2.3\% $\mathrm{SiO}_{2}$ and LDPE-3.3\% $\mathrm{SiO}_{2}$, where a third contribution to the crystalline morphology constituted by 40 droplet like structures can be visualized. Finally, for higher loads of nanoparticles (LDPE-7.9\% $\mathrm{SiO}_{2}$ and LDPE-16.5\%-SiO$)_{2}$ ), the morphology corresponding to the milled LDPE without particles seems to be recovered. Therefore, although no significant differences are observed in terms of the degree of crystallinity

45 (Figure 2, $\chi_{c}$ ), AFM points out changes with milling and the presence of nanosilica particles, as reflected in the fine morphology associated to lamellar shape and size.
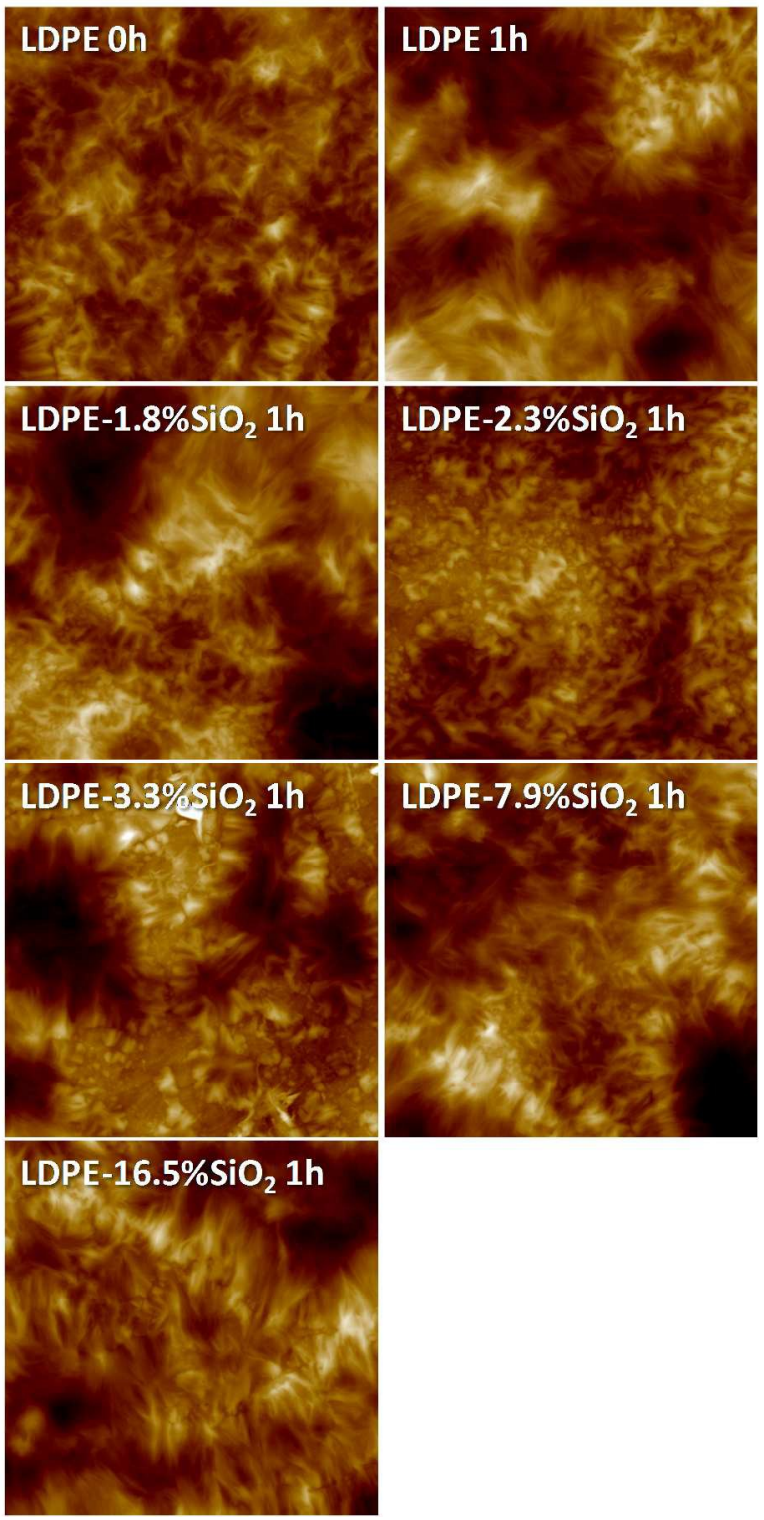

${ }_{50}$ Fig. 3 Height AFM images for samples with different nanosilica content (scan size is $10 \times 10 \mu \mathrm{m}^{2}$; color scale $500 \mathrm{~nm}$ ).

It is also worth mentioning that there is no direct evidence of the presence of the silica nanoparticles on the surfaces of the 55 samples, which suggest that the nanofiller tends to locate in the polymer bulk rather than on the outer surface of the material. In fact, when the samples are ultramicrotomed the presence of silica nanoparticles is clearly evidenced by AFM [13].

\section{${ }_{60}$ FTIR-ATR}

The melting process of LDPE was followed by FTIR-ATR, trying to visualize at a molecular scale the influence of the presence of silica nanoparticles. Normalized FTIR-ATR spectra recorded at $40^{\circ} \mathrm{C}$ and $140^{\circ} \mathrm{C}$ are shown in Figure 4. The spectra ${ }_{65}$ show changes occurring in the polymer when cooling from $140^{\circ} \mathrm{C}$ (liquid) to $40^{\circ} \mathrm{C}$ (solid). Polyethylene chains can be found in essentially two configurations: planar zig-zag, representing the crystalline regions of the polymer [32], and random configuration, only restricted by the conservation of bond angles 70 and distances [33], which constitutes the amorphous regions. 
However, the random configuration becomes partially oriented when the sample is stretched [34] and therefore, the spectrum of $\mathrm{PE}$ is usually represented by a superposition of the spectra arising from two different types of chain configurations.

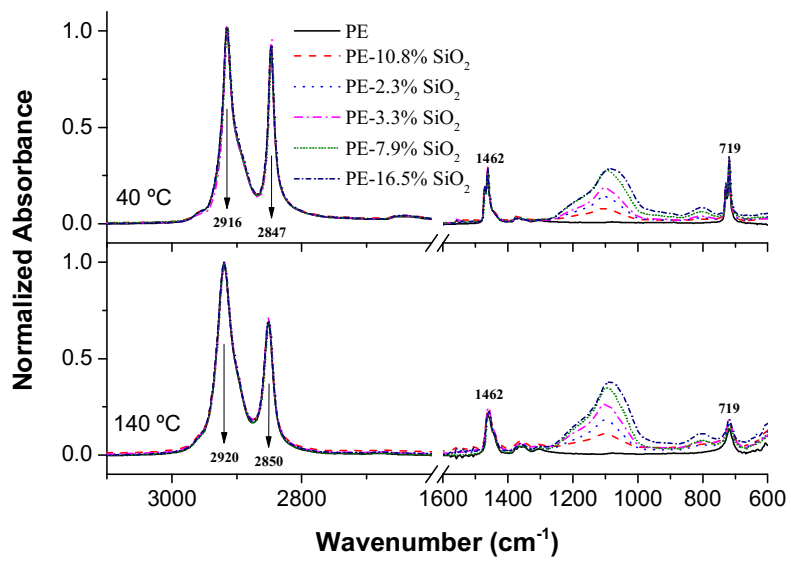

Fig. 4 FTIR-ATR spectra of the nanocomposites (LDPE; LDPE $1.8 \%$; LDPE $2.3 \%$; LDPE $3.3 \%$; LDPE $7.9 \%$; LDPE $16.5 \%$ of ${ }_{10} \mathrm{SiO}_{2}$ nanoparticles) at $40{ }^{\circ} \mathrm{C}$ (top) and $140{ }^{\circ} \mathrm{C}$ (bottom).

All the spectra show a wide band centered at about $1100 \mathrm{~cm}^{-1}$ that is assigned to the siloxane $\mathrm{Si}-\mathrm{O}-\mathrm{Si}$ bonds of the silica nanoparticles and that increases as the silica content increases 15 (Figure 4). It would seem that the temperature is influencing somewhat the absorbance of the Si-O-Si stretching but that apparent increase comes in fact from the normalization to the $\mathrm{CH}_{2}$ stretching band of the LDPE, which is affected upon melting. As for the PE bands, the most intense ones are the

20 asymmetric, $v_{\mathrm{a}}\left(\mathrm{CH}_{2}\right)$, and symmetric stretching, $v_{\mathrm{s}}\left(\mathrm{CH}_{2}\right)$, modes of the $\mathrm{CH}_{2}$ group, always present in hydrocarbons and different forms of PE [35]. These bands appear in the ATR spectra at 2916 $\mathrm{cm}^{-1}$ and $2847 \mathrm{~cm}^{-1}$, respectively (Figure 4,top). The bending mode of $\mathrm{CH}_{2}$ in polyethylene, $\delta\left(\mathrm{CH}_{2}\right)$, appears at about $1460 \mathrm{~cm}^{-1}$ 25 [36], and the rocking mode of the $\mathrm{CH}_{2}, \gamma_{\mathrm{r}}\left(\mathrm{CH}_{2}\right)$, at about $725 \mathrm{~cm}^{-}$ 1 . However, band splitting for the rocking and bending modes of methylene can be observed at $720 \mathrm{~cm}^{-1}$ and $1462 \mathrm{~cm}^{-1}$, respectively, (Figure 4 top), a feature that has been ascribed to the presence of crystalline phases in the PE, as reported by S. Krimm 30 et al. [36]. These doublets disappear when the temperature of the samples is well above the melting point, at $140{ }^{\circ} \mathrm{C}$ (Figure 4, bottom). There are other significant changes in the spectra when temperature increases: i) a very small shift of the $\mathrm{CH}_{2}$ stretching bands to higher energies; ii) a variation in the absorbance ratio 35 between asymmetric and symmetric stretching bands; and iii) a global reduction of the absorbances of the main PE bands.

A simple way of monitoring the melting process is to carefully analyze the vanishing of the doublets associated to the crystalline phase. On the other hand, if the physical mechanisms 40 associated to other changes with temperature are known, it may be possible to extract valuable information about the PE dynamics under the influence of the presence of silica nanoparticles. As an example, different regions of the spectra have been considered (Figure 5), showing the evolution of the 45 absorbance with the temperature, band shifts and double peaks for the nanocomposite with a $3.3 \%$ by weight of silica nanoparticles. Similar results were obtained for the other samples. In order to monitor the changes in the crystallization process, the peaks at $729 \mathrm{~cm}^{-1}$ and $1470 \mathrm{~cm}^{-1}$ associated to the crystalline ${ }_{50}$ phases have been considered. A convenient way to analyze this effect is to study the ratio between the absorbance of the crystalline peak taken at its maximum and that of the closest minimum associated to the same mode in the amorphous phase. These ratios have been plotted in Figure 6 for the different 55 compositions studied.
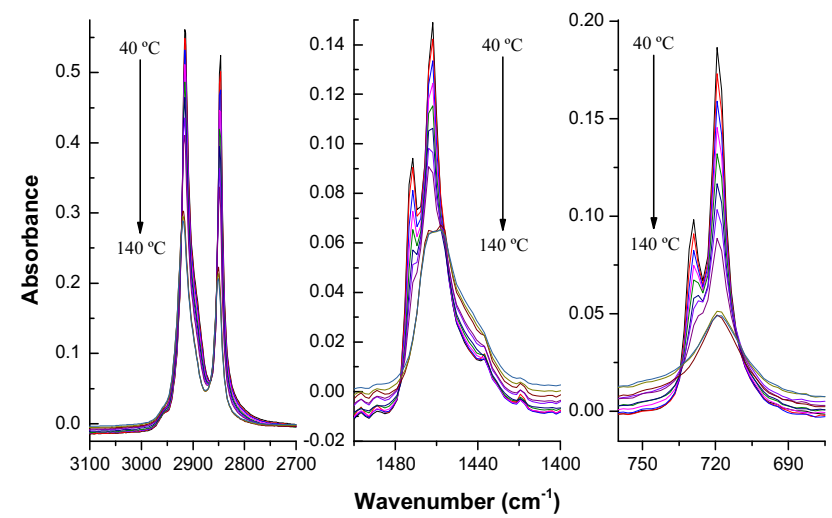

Fig. 5 Evolution of the spectra with the temperature for the sample LDPE-3.3\% $\mathrm{SiO}_{2}$ 1h. Left: aliphatic stretching vibrations $60\left(v_{\mathrm{a}}, v_{\mathrm{s}}\right)$; Center: bending mode of $\mathrm{CH}_{2}, \delta\left(\mathrm{CH}_{2}\right)$; Right: rocking mode of the $\mathrm{CH}_{2}, \gamma_{\mathrm{r}}\left(\mathrm{CH}_{2}\right)$.
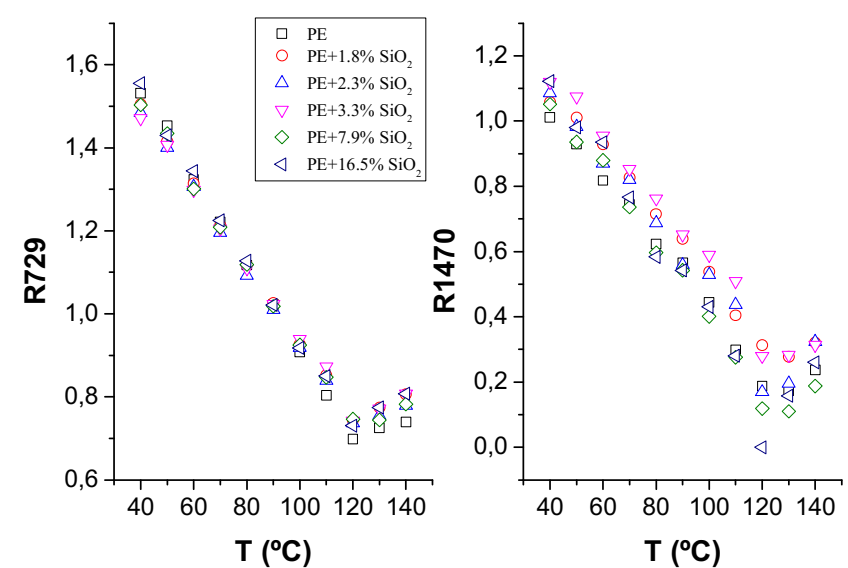

${ }_{65}$ Fig. 6 Absorbance ratios of the bands corresponding to the rocking $\gamma_{\mathrm{r}}\left(\mathrm{CH}_{2}\right)$ and bending $\delta\left(\mathrm{CH}_{2}\right)$ modes of $\mathrm{CH}_{2}$ as a function of temperature and nanosilica content. Left: $\mathrm{R}_{729}$. Right, $\mathrm{R}_{1470}$

As can be seen, both band ratios remain virtually constant 70 when cooling from $140^{\circ} \mathrm{C}$ to $120^{\circ} \mathrm{C}$ as no crystalline phase is formed at all. However, at about $115^{\circ} \mathrm{C}$, the absorbance begins to increase indicating the formation of crystallites in which specific interactions are the responsible of the appearance of a new peak for the $\mathrm{CH}_{2}$ rocking and bending modes. Beyond this point, the 75 absorbance ratios increase constantly over the whole range of temperatures down to $40^{\circ} \mathrm{C}$. Two possible interpretations can be done: either there is a continuous increase of the crystalline phase or there is a continuous increase of the density of the material due to cooling. Although both effects can contribute to the observed 80 behavior, it seems reasonable to think that the increase in density be the most important contribution. In fact, the DSC experiments have shown that the offset of the exothermic peak due to crystallization appears at about $70^{\circ} \mathrm{C}$ [13], when the crystallization has taken place. On the other hand, the silica 85 nanoparticles do not seem to have any effect, either on the crystallization process or on the polymer dynamics. 
When the integrated absorbance for the main IR bands is considered similar profiles are obtained. There is a continuous increase of this parameter as the temperature increases, with an important change of slope at $120^{\circ} \mathrm{C}$, which can be explained by ${ }_{5}$ the increase of density upon cooling. The most important change of slope is associated to the appearance of crystalline phase from the amorphous phase, but nothing else can be said about the dynamics of the PE.

Finally, in order to study the global polymer dynamics of 10 polyethylene, the absorbance ratio between the bands of the $\mathrm{CH}_{2}$ stretching modes has been considered. The ratio, $\mathrm{A}_{2916} / \mathrm{A}_{2847}$, and its first derivative have been plotted in Figure 7 as a function of temperature for all the different contents in $\mathrm{SiO}_{2}$. It is observed how the ratio decreases when cooling down. Since the total 15 absorbance increases with the temperature, the absorbance for the $\mathrm{CH}_{2}$ asymmetric stretching mode has to diminish more slowly than that corresponding to the $\mathrm{CH}_{2}$ symmetric stretching mode. A possible explanation is the different changes in the dipole moment with the volume [22]. Asymmetric vibrations have a 20 higher change in the dipole moment when the free volume increases with temperature. In other words, the continuous increase in the band ratio might be due to an increase in free volume that provides more space for segmental motions, allowing larger changes in the dipole moment of the asymmetric vibrations 25 and then a higher probability for the absorption to take place (higher absorbances). Therefore, when a certain polymer relaxation occurs, one would expect an enhancement of this effect or a change in the slope when plotting the absorbance ratio as a function of temperature. In fact, two important changes of slope 30 are visualized in Figure 7, which may be ascribed to thermal transitions of the PE.

To better identify the temperature at which those transitions occur faster, the first derivative of the absorbance ratio has been plotted in Figure 7 (bottom). Regardless the nanosilica content, 35 two maxima can be observed at about $55^{\circ} \mathrm{C}$ and $120^{\circ} \mathrm{C}$, which nearly match the two thermal transitions obtained by DSC during heating and cooling scans [13]. The relaxation occurring at $120^{\circ}$ is entirely associated to the crystallization process [37], while that centred at $60^{\circ} \mathrm{C}$ can be attributed to a thermal relaxation, although 40 its microscopic origin is still unclear. Up to present two are the possible explanations for that relaxation process. Some authors believe it comes from $\beta$-process, which is shifted to high temperatures because of the constraints imposed by the high entanglement density in the amorphous phase after ${ }_{45}$ crystallization, while others, assigned this relaxation to the $\alpha_{1^{-}}$ process or an intralamellar slip process of mosaic blocks [37].

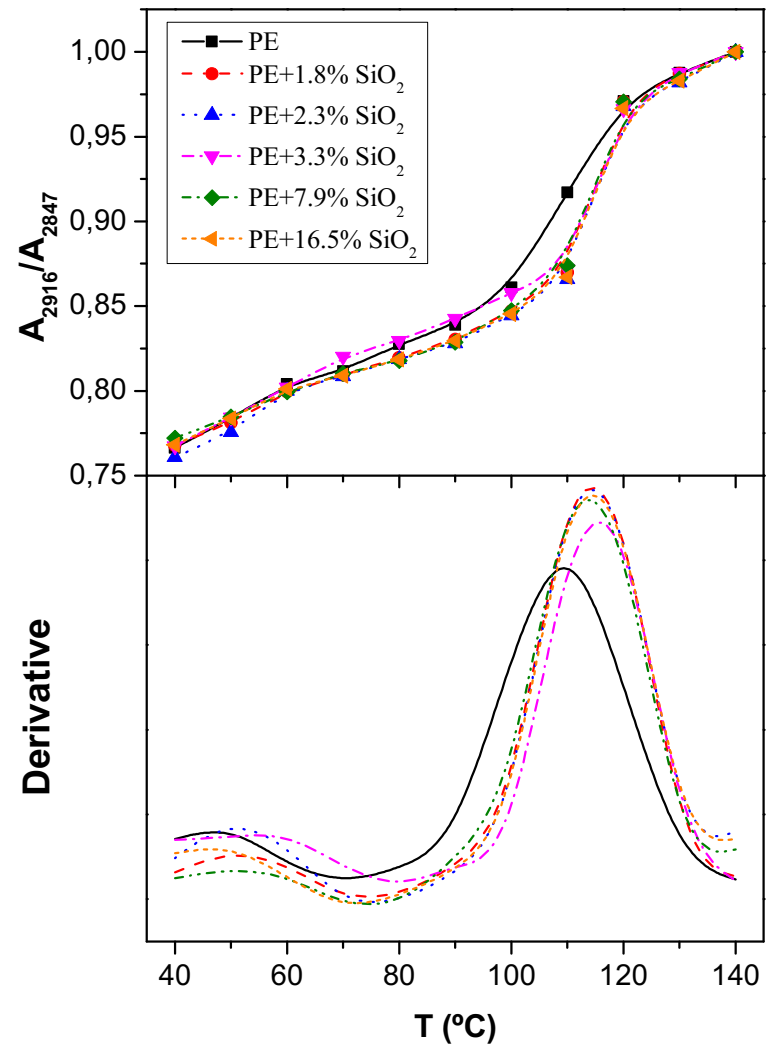

Fig. 7 Absorbance ratio $\mathrm{A}_{2916} / \mathrm{A}_{2847}$ versus temperature (top) and ${ }_{50}$ its first derivative (bottom) for different contents in $\mathrm{SiO}_{2}$ (dotted lines are the same as above)

In terms of the effect of the presence of silica nanoparticles and by using this band ratio, it is possible to see that the 55 relaxation takes place at lower temperatures when there are no particles within the polymer. Besides, in the absence of silica the crystallization process seems to be more heterogeneous as it occurs along a wider interval of temperatures. This can be deduced from the first derivative of the absorbance ratio (Figure 7 60 bottom) as a broader peak associated to the crystallization. Finally, at least from $1.8 \%$ to $16.5 \%$ wt of silica nanoparticles, the plots are coincident, which indicates that the PE dynamics is only slightly affected by the presence of a small amount of nanoparticles (lower than 1\%), remaining then constant at higher ${ }_{65}$ loads of filler.

\section{Conclusions}

The use of FTIR-ATR spectroscopy to monitor IR spectra of the samples with temperature has allowed proposing an easy method to study thermal transitions as well as specific interactions at a 70 molecular scale in a thermoplastic nanocomposite of LDPE and $\mathrm{SiO}_{2}$. The analysis of the band absorption ratio of the aliphatic stretching vibrations $\left(\mathrm{A}_{2916} / \mathrm{A}_{2847}\right)$ facilitated to obtain information of the overall polymer structure and dynamics. Thus, the relaxation phenomenon at about $55^{\circ} \mathrm{C}$ in the nanocomposites

75 filled with silica nanoparticles was found to be slightly shifted to lower temperatures for LDPE without nanoparticles. Nanocomposites are usually claimed to produce extraordinary changes in the properties due to the high surface in contact with the matrix. In the case of LDPE-nanosilica, the degradation 80 temperature of LDPE increases only when the amount of $\mathrm{SiO}_{2}$ is relatively high, although its presence has not a noticeable catalytic or inhibiting effect on the decomposition of the polymer. 
The structural, morphological and thermal characterization of the nanocomposites did not reveal remarkable changes at low loads of filler either, indicating that in the case of LDPE-silica nanocomposites, where no strong interactions between the 5 polymer and filler take place, the volume fraction of nanoparticles must be relatively high in order to produce changes in the bulk properties.

\section{Acknowledgements}

The authors acknowledge financial support from projects 10 MAT2007-65752 and MAT2010-16815, and the assistance of S. Martínez with the TGA and FTIR-ATR experiments.

\section{Notes and references}

${ }^{a}$ Department of Materials Science and Engineering, IQMAAB, Universidad Carlos III de Madrid. Av. Universidad 30, 28911, Leganés, SPAIN.E-mail: javid@ing.uc3m.es

${ }^{b}$ Departamento de Química y Edafología, Universidad de Navarra, 20 31080, Pamplona, Spain.E-mail: gaitano@unav.es

Name, B. Name and C. Name, Journal Title, 2000, 35, 3523.

\section{References}

1. A.P. Kumar, D. Depan, N.S. Tomer, R.P. Singh, Prog. Polym. Sci., 2009, 34, 479.

2. R. Zhao, P. Torley, P.J. Halley, J. Mater. Sci., 2008, 43, 3058 .

30 3. S.S. Ray, M. Okamoto, Prog. Polym. Sci., 2003, 28, 1539.

4. A. Yebra-Rodríguez, P. Alvarez-Lloret, C. Cardell, A.B. Rodríguez-Navarro, App. Clay Sci., 2009, 43, 91.

5. S. Molinaro, M.C. Romero, M. Boaro, A. Sensidoni, C. Lagazio, M. Morris, J. Kerry, J. Food Eng., 2013, 117, 113.

35 6. S.K. Sahoo, D.W. Kim, J. Kumar, A. Blumstein,A.L. Cholli, Macromolecules, 2003, 36, 2777.

7. H. Shinzawa, M. Nishida, T. Tanaka, W. Kanematsu, Vib. Spectrosc., 2012, 60, 50.

8. J. González-Benito, G. González-Gaitano, Macromolecules, 2008, 41, 4777.

9. J.Y. Nam, S.S. Ray, M. Okamoto, Macromolecules, 2003, 36, 7126.

10. F. Perrin-Sarazin, M.T. Ton-That, M.N. Bureau, J. Denault, Polymer, 2005, 46, 11624.

45 11. S. Zhao, L.S. Schadler, H. Hillborg, T. Auletta, Compos. Sci. Technol., 2008, 68, 2976.

12. J. González-Benito, J. Martínez-Tarifa, M.E. SepúlvedaGarcía, R.A. Portillo, G. González-Gaitano, Polym. Test., 2013, 32, 1342.

50 13. D. Olmos, E. Rodríguez-Gutiérrez, J. González-Benito, Polym. Compos., 2012, 33, 2009-.

14. Y. Zhou, V. Rangari, H. Mahfuz, S. Jeelani, P.K. Mallick, Mat. Sci. Eng. A-Sstruct., 2005, 402, 109.

15. C.G. Martins, N.M. Larocca, D.R. Paul, L.A. Pessan, Polymer, 2009, 50, 1743.

16. J. González-Benito, J. Colloid Inter. Sci., 2003, 267, 326.

17. P Bartolomeo, J.F. Chailan, J.L. Vernet, Eur. Polym. J., 2001, 37, 659 .

18. P.D. Castrillo, D. Olmos, J.M. Torkelson, J. González-Benito, 60 Polym. Compos., 2010, 31, 781.

19. D. Olmos, A. Loayza, J. González-Benito, J. Appl. Polym. Sci., 2010, 117, 2695.

20. C.J. Ellison, K.E. Miller, J.M. Torkelson, Polymer, 2004, 45, 2623.
65 21. F.A. Sanchez, M. Redondo, D. Olmos, M. Kuzmanovic, J. González-Benito, Macromolecular Symposia, 2014, 339, 48.

22. D. Olmos, E.V. Martin, J. Gonzalez-Benito, Phys. Chem. Chem. Phys., 2014, 16, 24339.

23. P.D. Castrillo, D. Olmos, D.R. Amador, J. González-Benito, J. Colloid Inter. Sci., 2007, 308, 318.

24. B.J. Ash, R.W. Siegel, L.S. Schadler. Macromolecules, 2004, 37, 1358 .

25. D. Olmos, F. Martínez, G. González-Gaitano, J. GonzálezBenito, Eur. Polym. J., 2011, 47, 1495.

75 26. D. Olmos, J.M. Martínez-Tarifa, G. González-Gaitano, J. González-Benito, Polym. Test., 2012, 31, 1121.

27. J. González-Benito, E. Castillo, J.F. Caldito, Eur. Polym. J., 2013, 49, 1747.

28. D. Olmos, A. García-López, J. González-Benito, Mater. Lett., 2013, 97, 8 .

29. P. Paika, K. K. Kar, Mater. Chem. Phys., 2009, 113, 953.

30. H.E. Kissinger, Anal. Chem., 1957, 29, 1702.

31. A. Aboulkas, K. El Harfi, A. El Bouadili, Energy Conv. Manag., 2010, 51, 1363.

85 32. C.W. Bunn, Transactions of the Faraday Society, 1939, 35, 482.

33. A. Charlesby, J. Polym. Sci., 1953, 10, 201.

34. S. Krimm, J. Chem. Phys., 1954, 22, 567.

35. J.J. Fox, A.E. Martin, Proceedings of the Royal Society of

$90 \quad$ London series A-mathematical and physical sciences, 1940, A175, 208.

36. S. Krimm, C.Y. Liang, G.B.B.M. Sutherland, The Journal of Chemical Physics, 1956, 25, 549.

37. Y. Men, J. Rieger, H.R. Endeler, D. Lilge, Macromolecules, 2003, 36, 4689. 